\title{
On the Reform of Solvency Rules for Insurance Undertakings in Europe Comments from the View Point of the Insurance Industry
}

\author{
by Norbert Konrath**
}

\section{Background}

The present efforts to reform the solvency supervision of insurance undertakings in the European Union focus on the so called "SOLO-PLUS" - concept, which means financial control with rules on own funds for:

- each individual insurance undertaking ("Solo"). (This concerns the reform of the current EU rules, which is what this article is about.)

- insurance undertakings belonging to an insurance group ("Plus")

(Proposal of the European Commission of 4th October 1995 for a "Directive on the supplementary supervision of insurance undertakings in an insurance group", which at this moment ${ }^{1}$ is still under deliberation in the European Parliament) and:

- insurance undertakings belonging to financial conglomerates ("Plus")

(This subject is dealt with by a mixed group of technical experts of the EU Banking and Insurance Committees as well as by working parties of the international associations of supervisory authorities worldwide. A recommendation or a proposal for a directive are not yet available.)

The discussion about the reform has to be seen in light of developments in the financial service sector (banks, insurance undertakings, security firms), which is currently marked by increasing competition, new products, the formation of groups and growing

* Director, Allianz Aktiengesellschaft, Königstrasse 28, 80802 Munich, Germany.

${ }^{1}$ Mid-October 1997. 
internationalization. As to insurance undertakings in the EU, this development has deliberately been encouraged by the Third Directives of 1992 launching the European Single Market (especially through the introduction of freedom of services and homeland control) whereby supervision of conditions and tariffs was largely abolished (deregulation).

The control of insurance undertakings is therefore basically financial supervision with the following key areas: technical provisions, investments and own funds (solvability). The supervisory authorities for insurance companies have not yet fully adapted to the new situation, but are nevertheless already asking for new "harmonized" legislation with three main objectives:

- better information of the supervisory authorities

- tighter control of intragroup transactions and above all

- higher solvency requirements.

Additionally, there is an ongoing discussion about the competence of the various supervisory authorities.

This forms the background of the present discussion about the reform of the current (Solo) solvency rules in the European Union of which art. 25 of the Third Non-Life Directive and art. 26 of the Third Life Assurance Directive are the legal basis. According to these provisions the European Commission shall submit a report to the EU Insurance Committee "on the need for further harmonization of the solvency margin" by no later than June 30, 1997.

To prepare its report, the European Commission sent questionnaires to the supervisory authorities of the EU Member States, to the Comité Européen des Assurances (CEA) and to the Groupe Consultatif des Associations d'Actuaires des Pays des Communautées Européennes requesting them to deliver their answers by the end of 1996 . CEA and actuaries replied in time, whereas the report of the supervisory authorities was dated May 16, 1997.

The questionnaire of the European Commission is subdivided into five chapters:

- non-life insurance

- life insurance

- reinsurance

- admitted solvency elements

- future solvency rules.

The following presentation emphasises the answers of the insurers and of the actuaries. The information about the report of the working party on "solvency of insurance companies" set up by the Conference of Supervisory Authorities in the EU Member States is limited to a critical discussion from the insurers' viewpoint. Finally, the report of the European Commission of July 1997 will be shortly mentioned. For the basic knowledge of the present solvency rules for insurance undertakings, which is essential for 
the understanding of his report, the author refers, among others, to his contribution in the "Geneva Papers" No. 78 of January 1996.

\section{The insurers' viewpoint}

All groups interrogated by the European Commission agreed that the existing European solvency rules for insurance undertakings in the EU function satisfactorily. Neither the insurance industry and actuaries nor the supervisory authorities propose important changes, the latter however are in favour of considerably increasing the solvency requirements.

It is not just the insurance industry which points out that the few cases of financial difficulties in this sector in Europe are to be attributed to management errors (insufficient premiums and reserves especially with newly established and fast growing undertakings as well as hazardous investments) and that they could not have been prevented by an increase of the solvency requirements. The financial security of an insurance undertaking depends above all on sufficient premiums and technical provisions as well as on sound investments, which in the insurance industry are controlled by supervisory authorities. Own funds is only a financially less important fall back. There is no total safeguard against all risks of the insurance business and it would not be affordable either. Own funds are scarce and expensive. An additional advantage concerning security (and supervision) due to increased solvency requirements has to be balanced against the additional cost which at the end of the day has to be borne by the policyholders.

Based on this general position CEA, as the umbrella association of the European insurance industry, gave basically the following individual answers in reply to the different chapters of the European Commission's questionnaire:

\section{Non-Life Insurance}

Concerning the minimum guarantee funds the following was proposed:

- a reduction of groupings by classes of insurance; only two instead of three, i.e. liability credit and surety insurance on one side and all other risks on the other,

- an update and, for the future, an indexation of the amounts and

- an abolition of reductions in favour of mutual associations if not justified anymore.

Concerning the solvency margin CEA proposed

- to retain the present system of global assessment of risks (i.e. no detailed solvency requirements relating to individual categories of risks as with the "Risk-Based-Capital" system in the US),

- to retain the $18 / 16 \%$ premium index requirements only for new insurance undertakings at the most, and to otherwise standardise at $16 \%$ of gross written premiums of the business year (the difference being only 200,000.- ECU)

- to standardise the loss index at $23 \%$ (the difference compared with the present $26 / 23 \%$ two-class system being only $210,000 \mathrm{ECU})$ 


\section{Life assurance}

With respect to the minimum guarantee fund CEA favours the retention of one single amount for all classes of life assurance and for the rest the replies are the same as for the minimum guarantee fund in non-life assurance. As to the solvency margin it basically calls for:

- maintaining the global risk approach, the reference to mathematical reserves and to the $4 \%$ result, the open list of supplementary insurance, the rules for "Permanent Health Insurance", tontines and unit-linked life assurance business.

- reducing the $3 \%$ result or at least retaining it as well as the deductions for short-term insurance contracts,

- equal treatment of pension funds and unit-linked life assurance. (In both cases the investment risk is borne by the client.)

- According to the proposal of CEA, the reduction of the solvency margin to one third for health insurance belonging to non-life insurance, but being conducted according to the principles of life assurance, is to be maintained.

\section{Reinsurance}

CEA is in favour of maintaining the current (unconditioned) deduction (up to $50 \%$ of the reinsurers' share in last year's claims) for insurance business ceded to reinsurers. Upon question from the European Commission, the insurers also suggested a recognition of this deduction up to $100 \%$ for business ceded to "high quality" reinsurers. By high quality reinsurers the CEA understands

- professional reinsurers that are directly or indirectly supervised by state authorities,

- direct insurers subject to solvency control and with good solvency

- reinsurances carriers satisfying certain criteria (e.g. deposits, quality ratings or criteria for outward reinsurance controlled by supervisory authorities)

\section{Admitted solvency elements}

Here, the insurers favour the maintenance of the "status quo", which means

- no distinction (as with banks) between "high quality capital" and other solvency elements

- no restriction (and for the time being no enlargement) of the list of admitted solvency elements,

- continuing admission of a part of not yet paid up share capital, no general exclusion of own shares

- continuing admission of (non-life) mutual associations' claims against their members, continuing admission of secondary equity instruments admitted by the Third Directives (cumulative preferential shares, subordinated loans and similar securities) 
For life assurance CEA demands in addition the continuing admission of profit reserves (free part of the provisions for bonuses) and future profits. The calculation of the latter should (also) take past experience into account.

\section{Future regulations}

Concerning the possible reform of the current solvency rules for insurance undertakings, CEA is of the opinion that these should be expressed as a single European standard and not just as minimum requirements which Member States may exceed. In the past some EU Member States have in fact introduced additional solvency requirements without a European legal basis and they are demanding now that the other Member States should follow their example in order to avoid distortions of competition. If this was accepted, it would inevitably lead to never ending European insurance regulation. Furthermore, CEA disapproves that the US approach of "Risk-Based-Capital" be adopted, but does not oppose a harmonized, more differentiated use of sanctions by the supervisory authorities. It is not surprising that the "building block approach" or other essentials of the Capital Adequacy Directive are rejected as being inappropriate for the insurance industry. Finally, it should be mentioned that the insurance industry wishes to see a continuation of the annual solvency report to supervisors on the basis of the annual accounts. However, it does not oppose the presentation of available data (quarterly or upon request) to allow for an earlier intervention of supervisory authorities.

Following the proposal of the European Commission CEA recently dealt with some other questions, two of which went beyond the questionnaire and are worth mentioning in this context: the notion "mathematical reserves" and the treatment of equalisation provisions.

The expression "mathematical reserves" gives rise to extensive discussions. Here, the connection with solvency rules should be taken into account, which might from the outset exclude the widest possible definition in the sense of "all reserves that can or could be calculated or confirmed by an actuary or with the help of actuarial methods".

The term "mathematical reserves" is used in art. 19 of the First Life Assurance Directive of 13 th March, 1979, as a basis for the $4 \%$ solvency requirement in life assurance. Too wide a definition could entail exaggerated solvency requirements. The majority of working party members, who drafted the supervisors' solvency report to the European Commission, defined as "mathematical reserves" the life assurance provisions plus unearned premiums (less corresponding costs). According to art. 25 of the Insurance Accounts Directive unearned premiums can (Member States option) be included in the life assurance provision. This means that the term "mathematical reserves" does not just refer to mathematical methods but above all to the use of a biometric basis (mortality statistics) of calculation. However, one minor question, which is relevant for the definition and even more for competition, remains unanswered, i.e. how to deal with profit participation of policyholders? The intention is not to suggest the inclusion of the provision for bonuses in the basis for the calculation of the solvency requirements, but rather to point to an inegality caused by the present accounting rules. If bonuses allocated to individual policies are used for the increase of the expiry payments, they are included in the life-assurance provision and therefore in the basis of calculation for the solvency 
requirements. Other allocated profits to policyholders are shown in the balance sheet under the item "creditors arising out of direct insurance operations". Therefore they are not included in the calculation of the solvency margin. This means an influence of the solvency rules on the type of life-assurance business and should be eliminated.

Furthermore, it should be mentioned that in non-life insurance the notion of "mathematical reserves" only applies to annuities for bodily injury in liability -, accident and motor insurance, where for the time being it is not relevant in connection with solvency requirements. The latter is also true for the ageing provision in health insurance (belonging to non-life insurance) conducted according to the technical principles of life assurance. Even if this provision is calculated on an actuarial basis (mortality and morbidity statistics plus mathematical methods), an alignment with life-assurance would mean that solvency requirements for companies with a younger portfolio where ageing provisions are necessarily lower would be less demanding as compared with companies with a more balanced portfolio, although ageing provisions are a safeguard to keep premiums for older people under control.

Also the second topic, how to deal with equalisations provisions, has to be considered under the aspects of competition. First of all, we notice that in the European Union there are equalisation provisions as well as equalisation reserves for the same purpose, i.e. for the equalisation of fluctuations in claims ratios and for special (major) risks . According to art 30 of the Insurance Accounts Directive the difference is that the former have to be set aside as provisions "in compliance with legal or administrative requirements" and are therefore obligatory. In accordance with general principles, (voluntary) equalisation reserves would be considered as own funds, taxed and recognised as part of the solvency margin, whereas equalisation provisions are to be considered as creditors ("going concern" consideration), are tax deductible and not part of the admitted solvency elements. As the EU Member States are free to prescribe equalisation provisions or not (except for credit insurance where they are obligatory), but especially since in Great Britain for example, equalisation reserves are given preferential tax treatment, like equalisation provisions, this might lead to distortions of competition. Since it is clear that an insurance undertaking with inadequate provisions needs more own funds and vice-versa, this should be taken into account in an appropriate way in the assessment of the solvency of insurance companies and the distortion of competition be eliminated. The "Group Consultatif des Associations d'Actuaires des Pays des Communautées Européennes" also points to this in its letter to the European Commission of 19 December 1996 in reply to the above-mentioned questionnaire.

\section{The actuaries' point of view}

The study group of the European actuary associations submitted in fact two reports to the European Commission, i.e. a more technical one in reply to the questionnaire and one lobbying for the profession by proposing that an annual actuary's report on solvency for insurance managers and supervisory authorities be prescribed. The following presentation only deals with the first report.

The replies to the questionnaires correspond basically to those of the insurers and are in so far not referred to in order to avoid repetition. However, some differences and nuances seem to be quite interesting: 
As far as non-life insurance is concerned it is not surprising that the actuaries would like to go into more detail on the risks to which insurance undertakings are exposed and that, for the minimum guarantee fund as well as the solvency margin they are generally in favour of a more detailed break down by lines of business. However, no precise proposals (let alone figures) are presented for an amendment of the existing solvency rules. It is interesting to notice that according to their view the disadvantages of the lack of distinction between the different lines of business in the calculation of the margin (premium and claims index) - may be compensated by business line-oriented equalisation provisions.

Actuaries regret that the technical provisions in non-life insurance need not be as prudent as has been laid down for life assurance by the Third Life Assurance Directive. However, this does not lead them to the conclusion that an additional asset-linked index for investment risks is to be introduced in non-life insurance. This banking-sector approach is also rejected by the actuaries. Nevertheless, there seems to be a misunderstanding in so far as a prudent calculation of technical provisions is only considered guaranteed if the calculation (or confirmation) of these provisions by an actuary is obligatory. Two comments to this: the Insurance Accounts Directive regulates the technical provisions in non-life insurance in more detail than those in life-assurance. This led to more specific regulations in the Third Life-Assurance Directive. But first and foremost, all lines of insurance business have to meet the requirement of art. 56 of the Insurance Accounts Directive according to which the technical provisions must "at all times be such that an undertaking can meet all liabilities arising out of insurance contracts as far as can reasonably be foreseen". This clearly underlines the prudence principle.

In their reply the actuaries put more emphasis than CEA on the need to ease minimum guarantee fund requirements for small mutual associations as well as on the retention of reduced solvency requirements for mutual associations in non-life insurance entitled to call for supplementary contribution from their members.

As far as life-insurance is concerned it should only be mentioned that the actuaries' study group considers the solvency requirement of $3 \%$ of the capital at risk (2nd result) to be exaggerated, which by the way is in line with the calculations made within the framework of the US Risk Based Capital System.

In addition the actuaries underline quite rightly the connection between the level of provisions and the requirement for own funds. Interestingly the actuaries point out that from a theoretical point of view the solvency requirement of $4 \%$ of "mathematical reserves" need only be based on the minimum reserves, but not on amounts going beyond those that might have been included for reasons of prudence. From a business point of view this consideration seems to be adequate, since it would certainly be unjustified to expose a particularly prudent insurer to particularly high requirements with regard to own funds. In practice this differentiation seems difficult to apply, even with life-assurance and not only for tax reasons.

Concerning reinsurance the actuaries support the retention of the present regulation, although they too are of the opinion that up to 100 percent of the business ceded to "high quality reinsurers" should in principle be taken into consideration. However, they do not 
see any possibility of laying down clear criteria for determining what is a high quality reinsurer.

On the question of admitted own funds the actuaries favour a retention of the present list - including the implicit elements, especially profit reserves and future profits - as well as the present investment catalogue of the Third Directives. But they suggest two minor amendments: quality requirements for assets which are not used to cover technical provisions should be lower; it should not be allowed to consider own shares as assets in computation of the solvency margin. The actuaries' argument for the latter is the attempt to avoid "double gearing". The author of this presentation feels that what really counts is whether own shares are valuable and marketable.

As to the further harmonization of solvency rules the actuaries share the insurers' rejection to adopt the US Risk Based Capital System or parts of the Capital Adequacy Directive for the banking sector to the European insurance industry. They do not comment on the question whether future rules should be minimum or unified requirements, because from the viewpoint of actuaries it could not be answered. Finally, the actuaries are in favour of maintaining the annual publication of solvency reports (in line with the balance sheet) to the supervisory authorities and they recommend - quite correctly from the viewpoint of efficiency - that undertakings "under special supervision" have to report to the supervisory authorities also in the course of the business year if necessary.

\section{The supervisory authorities' point of view}

The opinions of the supervisory authorities are expressed in the above-mentioned report dated 16 May 1997 of the working party on solvency of insurance undertakings, set up by the conference of insurance supervisory authorities of the EU Member States. The author refrains from presenting this voluminous report (about 100 pages) with its 12 annexes, which, not surprisingly, has attracted the special interest of insurance undertakings, as they are the ones who have to meet the solvency requirements:

The approach taken by in the report - i.e. to see what are the risks insurance undertakings are exposed to and what are the measures to be taken to prevent them, so that solvency rules in the narrow sense only have a supplementary function - seems to be appropriate but is not consistently pursued due to quantification problems and obvious differences of opinion. The annexes of the report and especially its excellent summary of the US Risk-Based Capital System are quite instructive.

Concerning the actual contents it is generally welcomed that the existing solvency requirements for insurance companies in the EU can be considered as reliable and that therefore no substantial amendments of the system are suggested. The global risk approach is to be basically maintained with a distinction between minimum guarantee funds, guarantee funds and solvency margin. The US Risk-Based Capital is regarded as insufficiently proven, and the adoption of specific banking sector regulations is considered as not appropriate although certain elements of both regulations are taken into account. The authorities agree with the insurance industry that up to now financial difficulties could not have been avoided through higher solvency requirements. 
Although there is no evidence for the necessity to have additional solvency requirements, the general tendency of the report is precisely the increase of these requirements, albeit basically within the existing system. What is striking is the variety of opinions not only on the discussed amendments but also just on the interpretation of the present European solvency rules on the possibility of intervention on the part of the supervisory authorities as well as on the question of uniformity of future harmonized solvency rules in the European Single Market. Here too, one cannot help feeling that the business community, with its tendency towards internationalisation, has less problems with cross-border harmonization than national supervisory authorities.

Even if for the above-mentioned reason only relatively few amendments were approved by the majority of the working party members, this report has to be taken seriously because of the numerous suggestions it discusses, because of unclear upper limits for the solvency increases it suggests and because of the reservation of opinion for the coming discussions of the matter.

\section{To the main proposals of the report}

It suggests to considerably raise the minimum guarantee funds - at least to the level of the present inflation rate - providing alleviations for small companies in non-life insurance. For this they agree with insurers and actuaries, at least as regards the raise to the level of the inflation rate. What seems to be delicate is the intention to decide on all future adaptations by way of the "comitology" procedures in the Insurance Committee of the EU instead of accepting a simple indexation. The latter seems to be less costly and more predictable.

The threshold of 10 million ECU for premium income or 7 million ECU for claims in non-life insurance should be abolished, as suggested by the insurers, and in contrast to the request of the insurance industry the percentage should be generally fixed at least at the respective higher level, i.e. at 18 and $26 \%$. As already mentioned above, no justification is given for this rise and above all it is not explained if and how technical risks have increased in recent years. In addition to the premium and claims result a third index has been suggested, i.e. a technical provisions' index. The question is, whether this new index should be applied in addition or alternatively to the already existing ones (as is currently the case with the relation between premiums and claims index). The idea is to take the so-called "long tail business" into account. But it would mean that the higher - and hence possibly also the more prudent - the provisions, the higher the requirements for own funds.

If the proposal remained so undifferentiated insurers with equalisation provisions, for instance, would also have to provide more own funds than those without such provisions, although their security level is higher.

Furthermore, the proposal of an additional (fourth) index was discussed (no majority decision). It should correspond to a percentage (between 0 and $8 \%$ ) of the (possibly riskweighted) investments and is intended to provide for risks connected with investments. This would in fact be a copy of the regulations of the banking sector and a step towards the US Risk-Based Capital System. The approach which is typical of the insurance industry and according to which the volume of technical provisions is the measure for investments would be given up. 
As regards life-assurance the working party is well aware of the fact that the second result, i.e. the solvency requirement of $3 \%$ of the capital at risk could be exaggerated, but it calls for maintaining this level as well as for the retention of the first result of $4 \%$ of the mathematical provisions (uncontested by the insurers). But in this case too, a minority wants to see the introduction of an additional index which is directly linked to the riskweighted investments.

As regards the business ceded to reinsurers the working party could not warm to the idea of a higher recognition of business ceded to "quality reinsurers" and therefore proposed the retention of the present $50 \%$ threshold.

Not only did the working party suggest an increase of the minimum guarantee fund and the solvency margin in non-life insurance as well as possible additional indexes, it also supports changes in the basis for calculation for the actual solvency, which also result in higher financial requirements. The list of own funds included in the solvency rules as well as the list of admitted investments should be checked and closed, although these lists were updated and liberalised as recently as 1992 in connection with the work on the Third Directives. Thus, there is a risk of reregulation. According to the working party this should also lead to stricter requirements with regard to free assets, i.e. the assets covering the own funds, and leaves it to the discretion of the supervisory authorities to exclude generally admitted assets or own funds from the computation of the solvency margin, if their quality seems not to be sufficiently guaranteed (e.g. explicitly confirmed by an actuary or another expert). The latter should not only apply to the calculation of future profits in lifeassurance.

Finally, the working party of the supervisory authorities favours a possibility for intervention on the part of the supervisory authorities even if all solvency requirements are met. Insurers should show some understanding as far as insufficient premiums and technical provisions, risky investments or expansion problems are concerned. In the European Insurance Directives (1st and 3rd) as well as in a number of EU Member States explicit standards for the intervention of supervisory authorities in these cases already exist: Nevertheless, some supervisors seem to be of the opinion that in the case of regular solvency the supervisory authority has no possibility to intervene. In fact, this is where action should be taken. However, what seems delicate is to link an earlier intervention of the supervisory authorities to a certain percentage of the solvency margin. If intervention is taking place if, for instance "only" $150 \%$ of the solvency requirements are met, this would mean in practice a simple increase of the solvency requirements.

As a whole the report shows a tendency by the supervisory authorities to avoid being bound by uniform European solvency requirements for insurance undertakings, and to retain as much discretionary power as possible. The insurance industry does not oppose an appropriate use of supervisory instruments compatible with the actual situation of the company. On the other hand legal security and fair competition are so important that uniform solvency requirements in the EU should by no means be dispensed with.

\section{Outlook}

The European Commission has given a relatively short and rather preliminary report to the Insurance Committee in July 1997 with a press release of July 28th. According to these documents the Commission shares the opinion that "the current arrangements 
governing the solvency margin of insurance undertakings are working well, apart from a few weaknesses as regards the coverage of certain highly specific risks". This is a quotation. As such risks are mentioned specifically "long-term risks and investment risks in non-life insurance, the reinsurance risk and the risk connected with rapid variations in operating conditions". For these risks which the author does not consider so "highly specific" the Commission announces a proposal for changes in the present European solvency directives for 1998. This proposal shall - of course - also suggest an adaptation of the minimum amounts required. With regard to the legal character of the revised solvency the Commission is hesitating between the "single standard" concept favoured by the insurance industry to ensure equal conditions of competition in the Single Market and the "minimum harmonisation" concept which would allow for higher requirements, more flexibility for national supervisors and - one is tempted to add - a continuing need for further harmonisation.

Under the condition that the European Commission will publish its Directive proposal by the end of 1998 at the latest and that the European legislative procedure (opinion of the Economic and Social Council, reply of the European Parliament and decision by the Council of Ministers) will only take 18 months (not too pessimistic) and that the Member States will also obtain the same delay for the implementation and enforcement of the Directive (usual minimum) the amended solvency rules for insurance undertakings in the EU will be effective starting from year 2002.

In the meantime the parties involved should see to it that the financial implications of such a reform together with those from the Insurance Groups Directive and possible solvency requirements for insurance undertakings in financial conglomerates do not as a whole lead to an unjustified financial burden for the companies and thus finally result in a misallocation of capital and higher insurance prices for the consumers. 